\title{
Transient increase in alcohol self-administration following a period of chronic exposure to corticosterone
}

\author{
Joyce Besheera,b,c Kristen R. Fishera, Tessa G. Lindsaya , and Reginald Cannadya,b \\ aBowles Center for Alcohol Studies, University of North Carolina at Chapel Hill, Chapel Hill, North \\ Carolina 27599 \\ ${ }^{b}$ Curriculum in Neurobiology, University of North Carolina at Chapel Hill, Chapel Hill, North \\ Carolina 27599 \\ 'Department of Psychiatry, University of North Carolina at Chapel Hill, Chapel Hill, North Carolina \\ 27599
}

\begin{abstract}
Stressful life events and chronic stressors have been associated with escalations in alcohol drinking. Stress exposure leads to the secretion of glucocorticoids (cortisol in the human; corticosterone (CORT) in the rodent). To model a period of heightened elevations in CORT, the present work assessed the effects of chronic exposure to the stress hormone CORT on alcohol selfadministration. Male Long Evans rats were trained to self-administer a sweetened alcohol solution ( $2 \%$ sucrose $/ 15 \%$ alcohol) resulting in moderate levels of daily alcohol intake $(0.5-0.7 \mathrm{~g} / \mathrm{kg}$ ). Following stable baseline operant self-administration, rats received CORT in the drinking water for 7 days. A transient increase in alcohol self-administration was observed on the first selfadministration session following CORT exposure, and behavior returned to control levels by the second session. Control experiments determined that this increase in alcohol self-administration was specific to alcohol, unrelated to general motor activation, and functionally dissociated from decreased CORT levels at the time of testing. These results indicate that repeated exposure to heightened levels of stress hormone (e.g., as may be experienced during stressful episodes) has the potential to lead to exacerbated alcohol intake in low to moderate drinkers. Given that maladaptive drinking patterns, such as escalated alcohol drinking following stressful episodes, have the potential to put an individual at risk for future drinking disorders, utilization of this model will be important for examination of neuroadaptations that occur as a consequence of CORT exposure in order to better understand escalated drinking following stressful episodes in nondependent individuals.
\end{abstract}

\section{Keywords}

stress; drinking; alcoholism; reinforcement; reward

\footnotetext{
(C) 2013 Elsevier Ltd. All rights reserved.

Correspondence: Joyce Besheer, Ph.D. (jbesheer@med.unc.edu), Bowles Center for Alcohol Studies, Thurston-Bowles Building; CB\#7178, University of North Carolina at Chapel Hill, Chapel Hill, North Carolina 27599, Voice: 919.843.9478; fax: 919.966.5679.

Publisher's Disclaimer: This is a PDF file of an unedited manuscript that has been accepted for publication. As a service to our customers we are providing this early version of the manuscript. The manuscript will undergo copyediting, typesetting, and review of the resulting proof before it is published in its final citable form. Please note that during the production process errors may be discovered which could affect the content, and all legal disclaimers that apply to the journal pertain.
} 


\subsection{Introduction}

Stressful or negative life events and chronic stressors have been associated with increased/ heavy drinking, increased drinking on days when stressful events occurred, and greater odds of binge drinking in nondependent, low to moderate drinking populations (Armeli et al. 2000; Carney et al. 2000; Jose et al. 2000; Dawson et al. 2005; Covault et al. 2007; Grzywacz and Almeida 2008; Kranzler et al. 2012). Maladaptive drinking patterns have the potential to put an individual at risk for future alcohol use disorders (O'Neill et al. 2001; Saha et al. 2006). Indeed, alcohol dependence and problem drinking have been associated with stressful life events in different populations (Johnson and Pandina 1993; Welte and Mirand 1995; Lloyd and Turner 2008; Slopen et al. 2011). Therefore, utilization of an animal model can allow for examination of adaptations in neural systems that may occur as a consequence of stress exposure which, in turn, can contribute to better understanding of escalated drinking following stressful episodes in nondependent individuals.

In preclinical studies, stress exposure (e.g., restraint, social, footshock) has been shown to increase (Nash and Maickel 1985; Rockman et al. 1987; Nash and Maickel 1988; Volpicelli et al. 1990; Lynch et al. 1999; Vengeliene et al. 2003; Funk et al. 2004; Chester et al. 2006; Lopez et al. 2011), decrease (Volpicelli et al. 1990; van Erp and Miczek 2001), or not alter alcohol consumption or preference (Myers and Holman 1967; Fidler and LoLordo 1996; Dayas et al. 2004); for review see (Becker et al. 2011). Several factors contribute to these diverse effects, such as strain, species, initial alcohol preference, timing of stress exposure, and different drinking protocols.

Stress exposure leads to the secretion of glucocorticoids (cortisol in the human; corticosterone (CORT) in the rodent). Therefore, the variation in the literature regarding the effects of stress on alcohol consumption is also likely affected by intensity, duration and type of stressor. In addition to stress exposure, elevations in glucocorticoids can be induced directly by exogenous administration of CORT. In the present work, CORT was administered in the drinking water for 1 week as a method to induce an episode of repeated and heightened elevations in glucocorticoids in intact (e.g., non-adrenalectamized) animals (Nacher et al. 2004; Gourley and Taylor 2009; Karatsoreos et al. 2010; Besheer et al. 2012). This method allows for the direct manipulation of CORT concentration and evaluation of fluid consumption, such that daily CORT dose can be determined. This is an added advantage of this model because of the potential for comparisons and increased replicability between laboratories in future work (e.g., the effects of restraint stress exposure can differ dramatically between labs). We have previously shown that this exposure to CORT in the drinking water results in heightened plasma corticosterone levels while CORT rhythmicity is apparently maintained, albeit exaggerated (i.e., heightened CORT levels during the dark cycle and lowered CORT levels during the light cycle when the behavioral experiments occur - see (Besheer et al. 2012)). This is critical given that a potential consequence of some chronic CORT exposure methods (e.g., implantation of CORT-releasing pellets) is elimination of CORT rhythmicity (Leitch et al. 2003), and disruptions in circadian rhythmicity can impact alcohol drinking (Spanagel et al. 2005). Further, disrupted CORT response to hypothalamic-pituitary-adrenal (HPA) axis challenge is evident (Besheer et al. 2012), confirming that this passive administration of CORT has similar physiological consequence as chronic stress exposure (Mizoguchi et al. 2001; Raone et al. 2007; Mizoguchi et al. 2008).

In addition to the aforementioned physiological consequences, prolonged exposure to CORT in the drinking water results in blunted sensitivity to the interoceptive (discriminative stimulus) effects of moderate doses of alcohol (Besheer et al. 2012). This behavioral change is functionally dissociated from low CORT levels at the time of testing, and likely 
modulated by CORT-induced adaptations in neurobiological systems that modulate sensitivity to alcohol (Besheer et al. 2012). Interoceptive drug effects can influence drug seeking behavior (Stolerman 1992; Wise et al. 2008), therefore, we sought to examine the effects of repeated CORT exposure on self-administration of moderate levels of alcohol. As such, we examined operant self-administration in Long Evans rats trained to lever press for a sweetened alcohol solution ( $2 \%$ sucrose (w/v), $15 \%$ alcohol (v/v)) or water. A sweetened alcohol solution was used as we determined from pilot experiments that this concentration resulted in stable operant responding over time and allowed animals to achieve physiologically relevant and moderate alcohol doses (e.g., $0.5-0.7 \mathrm{~g} / \mathrm{kg}$ ), such that the results would potentially be relevant to understanding escalated alcohol drinking in low to moderate drinking populations.

\subsection{Methods}

\subsubsection{Animals}

Male Long Evans rats (Harlan Sprague Dawley, Indianapolis, IN) weighing 150 - $200 \mathrm{~g}$ upon arrival to the colony were individually housed in Plexiglas cages. Rats had free access to food and water. The colony room was maintained on a 12-h light/dark cycle (lights on at $7 \mathrm{am}$ ) and all experiments were conducted during the light portion of the cycle (between 10 am and noon. Animals were under continuous care and monitoring by veterinary staff from the Division of Laboratory Animal Medicine (DLAM) at UNC-Chapel Hill. All procedures were also carried out in accordance with the NIH Guide to Care and Use of Laboratory Animals and institutional guidelines.

\subsubsection{Apparatus}

Self-administration chambers (Med Associates, Georgia, VT) measuring $31 \times 32 \times 24 \mathrm{~cm}$ were located within sound-attenuating cubicles and equipped with an exhaust fan that provided ventilation and masked external sounds. The left and right wall of each chamber contained one liquid receptacle and a response lever. Lever press responses activated a syringe pump (Med Associates) that delivered $0.1 \mathrm{ml}$ of solution into the receptacle across a 1.66-s period. A stimulus light located above each response lever was illuminated during pump activation. Lever presses during reinforcer delivery were recorded, but produced no programmed consequence. All chambers were interfaced (Med Associates) to a computer programmed to control sessions and record data. The locomotor assessments were conducted in clear Plexiglas chambers measuring $43.2 \times 43.2 \mathrm{~cm}$ (Med Associates). Two sets of 16 pulse-modulated infrared photobeams were located on opposite walls of the chambers to record ambulatory movements in the $\mathrm{x}-\mathrm{y}$ (horizontal) plane. The chambers were interfaced to a computer that was programmed to record the number of horizontal photo-beam breaks to determine the distance traveled $(\mathrm{cm})$ in the open field. The percent of distance traveled $(\mathrm{cm})$ and the percent of time $(\mathrm{sec})$ spent in the center in the center $(21.6 \times$ $21.6 \mathrm{~cm}$ ) of the open field was also calculated.

\subsubsection{Alcohol and Sucrose Self-administration Training Procedures}

Training procedures were similar to those described in (Besheer et al. 2008; Besheer et al. 2008; Besheer et al. 2010; Cannady et al. 2012). Rats received one 30-min selfadministration session each day (M-F) and both levers were maintained on a fixed ratio 2 (FR2), such that every $2^{\text {nd }}$ response on either lever resulted in reinforcer delivery corresponding to that lever (i.e., alcohol, water). A sucrose-fading procedure was used such that alcohol was gradually added to the $10 \%(\mathrm{w} / \mathrm{v})$ sucrose solution. The exact order of exposure was as follows: 10\% sucrose (w/v)/2\% (v/v) alcohol (10S/2A), 10S/5A, 10S/10A, 5S/10A, 5S/15A, 2S/15A. There were 2 sessions at each concentration. After sucrose fading, 
self-administration sessions with sweetened alcohol $(2 \mathrm{~S} / 15 \mathrm{~A})$ and water as the reinforcers continued for the remainder of the study.

Another group of rats was trained to self-administer sucrose $(0.3 \% \mathrm{w} / \mathrm{v}) \mathrm{vs}$. water using the same procedures with the exception that alcohol was not added to the reinforcer. The order of sucrose fading exposure was as follows: $10 \mathrm{~S}, 5 \mathrm{~S}, 2 \mathrm{~S}, 1 \mathrm{~S}, 0.5 \mathrm{~S}, 0.3 \mathrm{~S}$. There were 2 sessions at each concentration.

\subsubsection{Experiments}

Experiment 1. Effects of CORT exposure on alcohol self-administration-Rats received 20 days of baseline alcohol self-administration training at the $2 \mathrm{~S} / 15 \mathrm{~A}$ concentration. Immediately after the final baseline session, tail blood was collected to determine baseline plasma CORT levels. After the blood collection, rats were given one bottle (1-ml graduates) fitted with a ball bearing stopper (to limit spillage) containing CORT $(300 \mu \mathrm{g} / \mathrm{ml} ; \mathrm{n}=12)$ or water ( $\mathrm{n}=10)$ as the sole available fluid for 7 days ( $24 \mathrm{~h}$ daily access). The CORT concentration was selected based on our previous work (Besheer et al. 2012). Rats were weighed daily and the fluid was measured and changed daily. During the CORT exposure, two rats routinely had empty CORT-filled bottles and as such, were excluded from the experiment. This CORT exposure protocol and concentration were used in all the experiments. On Day 6 of CORT exposure, rats experienced a chamber re-exposure session, in which rats were placed in the self-administration chambers for 10 min with only the fan on (the levers were retracted and no fluid was available). This re-exposure was used to rehabituate the rats to the transport from the colony to the testing room and to the operant chamber, as a pilot experiment had shown a significant rise in plasma CORT levels in controls after a self-administration session without this re-exposure session. Immediately upon completion of Day 7, rats experienced a standard self-administration session and tail blood was collected immediately after the conclusion of this session for determination of plasma CORT and blood alcohol level. For one rat in the CORT group, not enough blood was collected, and blood alcohol level was not determined. Self-administration was evaluated on 3 additional days, but tail blood was not collected after those sessions, given that we were concerned that the frequent tail blood collection could disrupt selfadministration behavior. After the self-administration sessions, the liquid receptacles were inspected for residual fluid and none was detected.

\section{Experiment 2. Effects of CORT exposure on sucrose self-administration-To} determine whether changes in self-administration performance were specific to alcohol reinforcement, a behavior-matched sucrose self-administration group was tested $(\mathrm{n}=12)$. Procedures for this group were identical to the alcohol group with the exception that the rats were trained to self-administer $0.3 \%$ sucrose $(\mathrm{w} / \mathrm{v})$ vs. water ( 25 days of baseline training at the $0.3 \%$ sucrose concentration). This sucrose concentration was selected because daily response levels were similar to those observed in the alcohol self-administration group (Experiment 1). For this group, a within subjects design was used (treatment order - CORT or Water) was counterbalanced) given that we did not observe any changes in behavior between the groups (see Results) and as an effort to reduce the number of rats needed. Rats were given 2 weeks of self-administration training between the first and second 7-day Water/CORT exposure. After the self-administration sessions, the liquid receptacles were monitored for residual fluid and none was detected.

\section{Experiment 3. Effects of CORT exposure on blood alcohol clearance-To} determine whether 7 days of CORT exposure alters the clearance of alcohol, rats with a history of alcohol self-administration (greater than 40 baseline self-administration sessions) were exposed to CORT in the drinking water or water-only for 7 days ( $\mathrm{n}=8 /$ group). At the 
completion of Day 7, rats were administered alcohol ( $1 \mathrm{~g} / \mathrm{kg}$, IG) and tail blood was collected at 30, 60, 120 and 240 min later. This alcohol dose was tested, as alcohol intake following CORT exposure in Experiment 1 were within this range $(0.82-1.22 \mathrm{~g} / \mathrm{kg})$. In this experiment, blood was not collected for plasma CORT determination.

\section{Experiment 4. Effects of CORT synthesis inhibition on alcohol self-}

administration-To assess whether reduced CORT level was directly related to increased alcohol self-administration, rats were administered the CORT synthesis inhibitor metyrapone $(0,10,30 \mathrm{mg} / \mathrm{kg}, \mathrm{SC} ; \mathrm{n}=9) 90 \mathrm{~min}$ before a self-administration session. Rats had greater than 40 baseline self-administration sessions prior to testing. Tail blood was collected immediately following the self-administration session for plasma CORT determination. Further, the liquid receptacles were monitored after the test session for residual fluid and none was detected. A within subjects counterbalanced design was used with at least 1 week between tests. This experiment did not involve home cage CORT exposure.

\section{Experiment 5. Effects of CORT exposure on general motor activity and} anxiety-like behavior-To assess whether CORT treatment was related to nonspecific motor effects, a group of alcohol self-administration trained rats were exposed to CORT or water-only (n=6/group) for 7 days and upon completion of CORT exposure, locomotor behavior in an open field was assessed for $30 \mathrm{~min}$ as described above (Apparatus). The distance traveled in the center of the open field served as an index of anxiety-like behavior. The self-administration session was withheld on the locomotor test day. These locomotor assessments were 30 minutes in duration to parallel the duration of the self-administration sessions.

\subsubsection{Plasma CORT and blood alcohol determination}

All experiments occurred during $10 \mathrm{am}-12 \mathrm{pm}$. For blood collection, rats were briefly placed in a restrainer $(1 \mathrm{~min})$ and tail blood was collected. Blood samples were centrifuged immediately $\left(4^{\circ} \mathrm{C}\right)$, plasma was isolated and immediately placed on dry ice and stored at $-80^{\circ} \mathrm{C}$ until analysis. Plasma CORT was determined using a commercially available radioimmunoassay kit, according to the manufacturer's instructions (ICN Biochemicals, Costa Mesa, CA). Plasma alcohol was analyzed using an Analox Alcohol Analyzer (Model AM1, Analox Instruments USA Inc., Lunenburg, MA).

\subsubsection{Drugs}

Alcohol (95\% (w/v); Pharmco-AAPER, Shelbyville, KY) and sucrose were diluted in distilled water for the self-administration studies. CORT hemisuccinate (4-pregnen-11 $\beta, 21$ DIOL-3, 20-DIONE 21-hemisuccinate; Steraloids, Inc., Newport, RI) was dissolved in tap water (prepared daily) by the addition of $\mathrm{NaOH}$. The solution was then neutralized with $\mathrm{HCl}$, to a final pH of 7.0-7.4 (Gourley and Taylor 2009; Besheer et al. 2012). Metyrapone (2-Methyl-1,2-di-3-pyridyl-1-propanone; Sigma-Aldrich) dose was selected based on our previous work (Besheer et al. 2012) and was suspended in a $0.5 \%$ carboxymethocellulose solution (vehicle) and injected subcutaneously (SC) at a volume of $2 \mathrm{ml} / \mathrm{kg}$.

\subsubsection{Data analysis}

Self-administration data and plasma CORT levels were analyzed using analysis of variance (ANOVA), with repeated measures (RM) where appropriate. Alcohol intake $(\mathrm{g} / \mathrm{kg}$ ) was estimated based on rat body weight and number of reinforcers delivered. Based on the a priori hypothesis that group differences in self-administration would be accompanied by changes in the pattern of alcohol-lever responding across time, planned comparisons (t-tests) 
were used to explore significant main effects of time and group in the absence of a time by group interaction. Blood alcohol clearance was analyzed using similar parameters as described in (Gorin-Meyer et al. 2007; Cannady et al. 2012). Linear regression analysis was performed for each animal and derived parameters from the linear portion of the clearance curve $(10-240 \mathrm{~min})$. Derived regression analysis parameters included: estimated blood alcohol concentration at $0 \mathrm{~min}$ (y-intercept), estimated clearance rate $(\mathrm{mg} / \mathrm{dl} / \mathrm{min}$; slope of the regression line), and estimated clearance time ( $\mathrm{min}$; $\mathrm{x}$-intercept of regression line). The area under the clearance curve was also determined. Average fluid consumption and weight gain across the 7-day fluid exposure were analyzed using unpaired t-tests, with the exception of Experiment 2 for which paired t-tests were used. Post-hoc analyses (Newman Keuls) were used to explore significant main effects and interactions. Pearson product moment correlations were used to confirm the relation between blood alcohol concentration and alcohol intake. Statistical significance was declared at $\mathrm{P} \unlhd \mathbf{0} .05$.

\subsection{Results}

\section{Experiment 1. Effects of repeated CORT exposure on alcohol self-administration}

To assess whether repeated elevations in CORT induced an alteration in alcohol selfadministration, self-administration trained rats were exposed to CORT for 7 days. Average fluid consumption, weight change, and CORT dose consumed are shown in Table 1. Importantly, similar total fluid intake and weight gain between the Water and CORT groups indicates that these factors likely did not influence changes in self-administration.

A transient increase in alcohol self-administration was evident upon alcohol re-exposure following CORT exposure (Figure 1A). That is, the two-way ANOVA (Session as repeated factor; Group as a between factor), showed a significant main effect of Session $[F(4,72)=6.79, P<0.001]$, and a significant interaction $[F(4,72)=3.19, p<0.05]$. Importantly, prior to CORT exposure (baseline session), total alcohol lever responses were similar between the Water and CORT groups. However, a significant increase in total alcohol lever responses in the CORT group was observed on the first session following the CORT exposure relative to the Water group (Post-CORT Session 1; $<<0.05$ ) and relative to baseline $(\mathrm{p}<0.05)$. In the Water group a significant decrease in alcohol-reinforced responding from baseline was observed on the $3^{\text {rd }}$ session following water exposure $(\mathrm{p}<0.05)$; however, the reason for this decrease is not apparent, as behavior returned to normal levels on the subsequent session. No changes in water responses were observed (Table 1).

To further examine the increase in alcohol self-administration on the first session following CORT exposure, the pattern of alcohol lever responding on that session was examined (Figure 1B). A significant main effect of time $[F(2,36)=38.69, \mathrm{p}<0.001]$, and a significant main effect of group $[\mathrm{F}(1,18)=8.29, \mathrm{p}<0.05]$ were observed. Planned comparisons showed a significant increase in alcohol responses in the CORT group by $10 \mathrm{~min}$ and continuing throughout the session relative to the Water group $(\mathrm{p}<0.05)$, resulting in a significant increase in alcohol intake $(\mathrm{g} / \mathrm{kg})[\mathrm{t}=2.73, \mathrm{p}<0.01$; Figure $1 \mathrm{~B}$ inset $]$. There was a trend for a significant increase in blood alcohol concentration during this session (mean \pm S.E.M.: Water: $42.8 \pm 11.2 \mathrm{mg} / \mathrm{dl}$, CORT: $69.5 \pm 8.5 \mathrm{mg} / \mathrm{dl} ; \mathrm{p}<0.07$ ), which may be a reflection of the altered pattern of alcohol intake in the CORT group. That is, given that self-administration in the CORT group continued steadily throughout the session, blood alcohol concentration as determined by blood collection immediately upon completion of the session may not accurately reflect alcohol consumed during the latter part of the self-administration session. Importantly, for both groups, there was a significant positive correlation between blood alcohol concentration and alcohol intake [Water: $r=0.92$, $p<0.001$; CORT: $r=0.80, p<0.01$ ]. 
Analysis of plasma CORT levels showed a significant group by session (Baseline or PostWater/CORT Session 1) interaction $[\mathrm{F}(1,16)=7.4, \mathrm{p}<0.05$; Figure $1 \mathrm{C}]$. Plasma CORT levels in the CORT group were significantly lower than the Water group on the post-CORT session $(\mathrm{p}<0.007)$, and significantly lower than baseline $(\mathrm{p}<0.05)$. Importantly, CORT levels on the baseline session (prior to CORT exposure) were similar between the groups. This finding of reduced CORT levels following CORT exposure is consistent with our previous work using the same CORT exposure and is reflective of heightened elevations in CORT levels during the dark cycle and lower CORT levels during the light cycle corresponding to the time at which the behavioral testing occurs (Besheer et al. 2012), and confirms efficacy of the CORT exposure protocol.

\section{Experiment 2. Effects of repeated CORT exposure on sucrose self-administration}

To determine whether changes in alcohol self-administration following CORT exposure were specific to alcohol, sucrose self-administration was assessed following CORT exposure. Because a cross-over design was used in which the CORT exposure order was counterbalanced, separate two-way RM ANOVAs with exposure (CORT and Water) and testing order as factors were conducted to ensure no significant order effects. No significant main effects or interactions were observed on baseline sucrose lever responses or baseline plasma CORT levels, or sucrose lever responses after the assigned one week exposure. However, the analysis of plasma CORT levels after the assigned one week exposure showed a significant decrease in CORT levels as (main effect of exposure $[F(1,10)=13.04, p<0.01]$ ), consistent with confirmation of the efficacy of the CORT procedure. Given the lack of significant order effects, the two cohorts were combined.

Average fluid consumption, weight change, and CORT dose consumed are shown in Table 1. Total fluid intake was similar between the groups, but significantly less weight gain was observed in the CORT group relative to the Water group [t=2.2, $\mathrm{p}<0.05]$.

The two-way RM ANOVA showed a significant main effect of Session $[F(4,44)=8.40$, $\mathrm{P}<0.001]$, which was driven by lower sucrose-reinforced lever responding on the first session as compared to baseline $(\mathrm{p}<0.01)$. There was no significant main effect of group or interaction, indicating that CORT exposure did not alter sucrose self-administration. It is interesting that a similar reduction from baseline was not observed in the Water group of Experiment 1; however, it is not uncommon in our lab to observe slight reductions in operant self-administration following absence from the procedure (unpublished observations). This phenomenon has also been observed by others in relation to alcohol selfadministration (Oster et al. 2006). Total water responses across time or group did not differ (Table 1). Efficacy of the CORT exposure was confirmed as analysis of plasma CORT levels (two-way RM ANOVA) showed a significant main effect of group $[\mathrm{F}(1,11)=6.41$, $\mathrm{p}<0.05)$, and a significant interaction $[\mathrm{F}(1,11)=7.37, \mathrm{p}<0.05]$, with significantly lower CORT levels in the CORT group following CORT exposure $(\mathrm{p}<0.01)$ and as compared to baseline $(\mathrm{p}<0.05)$. These findings show that increases in alcohol self-administration following CORT exposure are specific to alcohol reinforcement and do not generalize to a non-drug reinforcer.

\section{Experiment 3. Blood alcohol clearance}

To determine whether CORT exposure altered alcohol clearance in rats with a history of alcohol self-administration, blood alcohol levels after administration of $1 \mathrm{~g} / \mathrm{kg}(\mathrm{IG})$ were examined following CORT exposure $(7 \mathrm{~d})$. Baseline self-administration data from the session prior to this assessment and fluid consumption are shown in Table 2. Blood alcohol levels were found to be unaltered by CORT exposure (Figure 3). A mixed two-way ANOVA (time as a repeated measure) showed that blood alcohol decreased across time 
$[\mathrm{F}(3,42)=286.05, \mathrm{p}<0.001]$ as would be expected, and this pattern was unaffected by CORT exposure (7 d), as no significant main effect of group or significant interaction were observed. Further, comparisons of estimated clearance rates and area under the curve did not differ (Table 3). Therefore, increased alcohol intake on the first session following CORT exposure is likely not due to altered clearance or blood levels of alcohol.

\section{Experiment 4. Effects of CORT synthesis inhibition on alcohol self-administration}

Metyrapone the CORT synthesis inhibitor was tested to determine whether reduced CORT level at the time of testing was functionally related to increased alcohol self-administration as observed in Experiment 1 on the first session following CORT exposure. As shown in Figure 4, alcohol self-administration was not altered by pretreatment with metyrapone. Total alcohol-reinforced responding and alcohol intake $(\mathrm{g} / \mathrm{kg})$ were unaltered. Total waterreinforced responding was also not altered by metyrapone pretreatment (mean \pm S.E.M.: Vehicle: $11.7 \pm 3.2 ; 10 \mathrm{mg} / \mathrm{kg}: 7.2 \pm 2.0 ; 30 \mathrm{mg} / \mathrm{kg}: 10.7 \pm 1.9)$. Consistent with its mechanism of action, metyrapone $(30 \mathrm{mg} / \mathrm{kg})$ produced a significant reduction in plasma CORT levels [RM ANOVA: $F(8,16)=5.10, \mathrm{p}<0.05]$. These results suggest that increased alcohol self-administration on the first session following CORT exposure in Experiments 1 is likely not a direct function of reduced CORT levels.

\section{Experiment 5. Effects of CORT exposure on general motor activity and anxiety-like behavior}

To determine whether CORT exposure altered general motor activity in rats with a history of lcohol self-administration, distance traveled was measured in an open field. Baseline selfadministration data from the session prior to this assessment and fluid consumption data are shown in Table 2. CORT exposure did not alter total distance traveled in the open field (mean \pm S.E.M.: Water: $3902.4 \pm 463.0 \mathrm{~cm}$; CORT: $4714.3 \pm 714.0 \mathrm{~cm}$ ). Examination of locomotor activity across the 30-min session showed similar patterns of behavior as the mixed factor ANOVA showed no significant group difference or interaction (Figure 5). However, the main effect of time was significant $[\mathrm{F}(29,290)=8.89, \mathrm{p}<0.05]$, which is indicative of habituation and suggests that both groups showed similar habituation in the open field. Distance traveled in the center of the open field was used as an index of anxietylike behavior. The percent of time spent in the center of the open field was similar between the groups (mean \pm S.E.M.: Water:12.1 $\pm 2.4 \%$; CORT:10.2 $\pm 2.4 \%$ ) and the distance traveled in the center of the open field relative to the overall distance traveled was also similar between the groups (mean \pm S.E.M.: Water:36.3 $\pm 7.4 \%$; CORT:30.0 $\pm 3.4 \%$ ), suggesting that CORT exposure did not induce an anxiety-like profile, and also that the majority of animals' time was spent in the perimeter of the open field (see later).

\subsection{Discussion}

The results of the present work show a transient increase in alcohol self-administration following a period of repeated and heightened elevations in CORT. This increase in selfadministration behavior was specific to alcohol, as sucrose self-administration and general locomotor behavior were unaltered at the same time period following CORT exposure. Further, the increase in alcohol intake was functionally dissociated from decreased CORT level at the time of testing, as metyrapone treatment did not alter alcohol self-administration behavior, suggesting that this behavioral change may be modulated by a CORT-induced neuroadaptive change in brain regions/circuits that modulate alcohol drinking. In addition to the advantages of utilization of the CORT procedure introduced above, similar fluid consumption between the Water and CORT groups and similar CORT dose consumed during the 7-day home cage exposure in each experiment that employed the CORT exposure 
procedure emphasize the replicability and further support the feasibility of utilization of this exposure method in future work.

Increased alcohol self-administration was evident on the first self-administration session following CORT exposure and returned to levels similar to the Water group on the subsequent sessions. This transient increase in behavior could suggest that the CORT exposure experience facilitated the emergence of an alcohol deprivation effect (ADE). An ADE is commonly observed after a period of alcohol abstinence and is characterized by a transient increase in alcohol drinking (Sinclair and Senter 1968). In addition to the majority of the literature showing the ADE using two-bottle choice alcohol drinking, the ADE has been demonstrated using operant self-administration methods (Heyser et al. 1997; McKinzie et al. 1998; Rodd et al. 2003; Schroeder et al. 2005; Oster et al. 2006; Sparta et al. 2009). Interestingly, there is evidence for an interaction between stress and the emergence of an $\mathrm{ADE}$ (evaluated by two-bottle alcohol drinking), when stress exposure occurs during the alcohol abstinence period (Overstreet et al. 2007; Knapp et al. 2011), lending further support for the suggestion of a facilitation of an ADE following CORT exposure in the present study. While alcohol self-administration was assessed on a fixed ratio schedule, it will be interesting to determine whether this increase in self-administration following CORT exposure is accompanied by increased motivational processes, as would be assessed under a progressive ratio schedule of reinforcement (e.g., (Besheer et al. 2008)) and as has been demonstrated in operant procedures evaluating the ADE (Rodd et al. 2003; Oster et al. 2006). Another interesting future direction would be to examine whether a potentiation of self-administration is evident after repeated cycles of CORT exposure, similar to the potentiation of the ADE using operant procedures after repeated cycles of abstinence and reexposure to alcohol (Rodd et al. 2003; Schroeder et al. 2005).

Importantly, the increase in alcohol self-administration immediately following the end of the 7-day CORT exposure was reinforcer specific. That is, in a parallel experiment (Experiment 2) sucrose self-administration was unaltered at the same time point following CORT exposure. This latter finding is intriguing given the literature showing that exogenous CORT administration or repeated stress exposure can induce anhedonic-like behavior, as evidenced by decreased sucrose consumption or impaired reward-related learning (Gourley et al. 2008; Gourley and Taylor 2009; Huang et al. 2011; Olausson et al. 2012); for review see (Willner 2005; Hill et al. 2012). However, it is possible that an anhedonic-like behavioral profile, as evidenced by decreased sucrose self-administration may emerge if self-administration was assessed at a later time point (e.g., 1 week after the cessation of CORT exposure), or in animals with less sucrose history, or perhaps at a higher or lower sucrose concentration.

Another potential explanation for the increase in alcohol self-administration immediately following CORT exposure is related to the interoceptive/subjective effects of the consumed alcohol. Given that drug taking behavior can be influenced by the interoceptive/subjective effects of drugs (Stolerman 1992; Wise et al. 2008), it is possible that sensitivity to the interoceptive effects of the self-administered/consumed alcohol were altered following CORT exposure. Interestingly, we have previously shown decreased sensitivity to the interoceptive effects of experimenter and self-administered alcohol following the same CORT exposure using an operant drug discrimination model (Besheer et al. 2012). In that work, rats showed decreased sensitivity to alcohol within similar dose ranges selfadministered in the present work (i.e., $0.5-1.7 \mathrm{~g} / \mathrm{kg}$ ). Therefore, decreased sensitivity to the interoceptive effects of the consumed alcohol following CORT exposure may be a potential explanation for the increase in alcohol self-administration. Further, this explanation may also be supported by the present finding that sucrose self-administration was not altered following CORT exposure. That is, the change in self-administration behavior was specific to alcohol (i.e., specific to a drug that has distinct interoceptive effects). 
Alternatively, the increase in alcohol-reinforced responding following CORT exposure may have been a function of a general nonspecific increase in locomotor activity. However, water lever responses and sucrose self-administration were unaltered, making these explanations less likely, and consistent with our previous work in which CORT exposure had no effect on response rate in another behavioral task (Besheer et al. 2012). Given preclinical data to suggest a relation between anxiety and alcohol drinking (Stewart et al. 1993; Spanagel et al. 1995; Overstreet et al. 1997), but see (Moller et al. 1997; Henniger et al. 2002), this is an important alternative explanation to assess. In an effort to evaluate the possibility of anxietylike behavior, within the context of the locomotor assessment, the relative amount of time spent in the center of the open field was examined. The groups did not differ in this measure, which may suggest the lack of anxiety-like behavior in the CORT group relative to the Water group. However, a key limitation of the present anxiety assessment is that the controls (i.e., Water group) did not spend a substantial amount of time exploring the center of the open field (i.e., $12 \%$ of the animals' time was spent in the center). Therefore, assessment of anxiety-like behavior in another task more suitable for the assessment of anxiety-like behavior (e.g., elevated plus maze) would be necessary before concluding the absence of anxiety-like behavior. Finally, alcohol clearance after CORT exposure was unaltered. This finding is consistent with previous work using a similar assessment in alcohol-naïve rats (Besheer et al. 2012) and makes an interpretation based on altered blood alcohol level or clearance of alcohol an unlikely explanation for the increase in alcohol self-administration.

A feature of the CORT exposure procedure is decreased plasma CORT levels during the time of day at which the behavioral experiments are conducted (i.e., heightened elevations in plasma CORT during the dark cycle when the fluid is consumed; (Besheer et al. 2012). Therefore, it was critical to determine whether the decreased CORT levels on the first selfadministration session following the conclusion of CORT exposure functionally contributed to the increase in alcohol self-administration on that session. Indeed, CORT level has been shown to directly modulate alcohol intake, as reductions in voluntary alcohol consumption are evident after adrenalectomy and restored with CORT treatment (Fahlke et al. 1994; Fahlke and Eriksson 2000). Administration of the CORT synthesis inhibitor metyrapone effectively decreased CORT levels to levels similar to those after CORT exposure in the drinking water; however, alcohol self-administration was not altered, making such an explanation less tenable. This finding is consistent with work showing that acute metyrapone pretreatment does not alter alcohol drinking (O'Callaghan et al. 2005), and another study showing that acute metyrapone reduced binge alcohol intake, but only at doses that also reduced sucrose consumption, suggesting a nonselective effect (Lowery et al. 2010). Further, the moderate alcohol dose achieved daily by the rats in the present study (approximately $0.7 \mathrm{~g} / \mathrm{kg}$ ) is likely not sufficient to induce a significant rise in CORT levels (Apter and Eriksson 2006), whereas in models of alcohol dependence, rats are exposed to high alcohol doses that can induce high levels of CORT and consequently lead to compromised HPA axis function (Richardson et al. 2008). Further, recent work has demonstrated a functional role for glucocorticoid receptors in alcohol dependent animals (Vendruscolo et al. 2012). Therefore, dependence models or drinking procedures in which high levels of alcohol are consumed daily may be more sensitive to modulation/ manipulations directly targeted at altering CORT levels. For example, adrenalectomy and CORT replacement has no effect on alcohol consumption in alcohol-non-preferring rats that consume low levels of alcohol (approximate median alcohol intake $0.2 \mathrm{~g} / \mathrm{kg}$ ), but in alcoholpreferring rats the same procedures resulted in a decrease and return to baseline drinking (approximate median alcohol intake $8 \mathrm{~g} / \mathrm{kg}$ in $24 \mathrm{~h}$ ), respectively (Fahlke and Eriksson 2000). Indeed, an interesting and highly relevant extension of the present work would be to assess the effects of the same CORT exposure procedure on alcohol drinking in alcohol dependent animals or in models that induce high alcohol consumption (e.g., binge drinking). 
Together, the findings of the present work suggest that the increased alcohol drinking following CORT exposure is dissociated from the decrease in CORT levels at the time of testing. A potential limitation of the present study is that plasma CORT was not evaluated in parallel to self-administration on every self-administration session following CORT exposure. Therefore, we do not know whether plasma CORT levels returned to baseline or Water control levels after that initial session. Regardless, the functional dissociation confirmed on the first self-administration session following CORT exposure suggests that the increase in alcohol drinking may be a consequence of underlying adaptations in neural systems that modulate alcohol reinforcement processes induced by prolonged CORT exposure. For example, the nucleus accumbens is a key brain region involved in the modulation of alcohol reinforcement (Hodge et al. 1994; June et al. 1998; Heyser et al. 1999; Hyytia and Kiianmaa 2001; Malinen and Hyytia 2008; Besheer et al. 2010), and there is a growing literature identifying neuroadaptations within this brain region as a consequence of chronic CORT or repeated stress exposure (Piazza et al. 1996; Tidey and Miczek 1997; Piazza and Le Moal 1998; Perrotti et al. 2004; Campioni et al. 2009; Gourley and Taylor 2009; Morales-Medina et al. 2009; Shoji and Mizoguchi 2010; Lemos et al. 2012). Therefore, future work will investigate the potential for neuroadaptive changes and their functional involvement in modulating escalated alcohol intake following chronic CORT exposure.

In conclusion, we find that immediately following a period of chronic CORT exposure there is a transient increase in alcohol self-administration behavior. Alterations in alcohol drinking have been shown to emerge over time after chronic stress exposure (Lowery et al. 2008; Lopez et al. 2011; Logrip and Zorrilla 2012), and while the present data provide evidence for the emergence of increased susceptibility to increased alcohol intake immediately following a period of repeated and heightened elevations in CORT, it will be interesting to determine whether repeated cycles of CORT exposure (i.e., experiencing repeated episodes of heightened elevations in stress hormone) potentiate and lead to persistence of these changes and whether re-acquisition of self-administration following an extinction period (relapse-like behavior) is potentiated by CORT exposure. Related to this latter point is the finding that prior stress history has been shown to potentiate relapse-like alcohol selfadministration in low alcohol drinking rats (Logrip and Zorrilla 2012). In sum, the results of the present work indicate that repeated exposure to heightened levels of stress hormones (e.g., as may be experienced during stressful episodes) has the potential to lead to exacerbated alcohol intake in low to moderate drinkers.

\section{Acknowledgments}

This work was supported in part by funds from the National Institutes of Health AA016009 (JB), AA019682 (JB), ABMRF/The Foundation for Alcohol Research (JB), and by the Bowles Center for Alcohol Studies. The authors would like to thank Drs. Clyde Hodge and Dr. Leslie Morrow for support and helpful discussions in regards to this manuscript, and to Andrew Whang for assistance with the blood alcohol experiment. Also, thanks to Dr. Hodge for the utilization of behavioral equipment.

\section{References}

Apter SJ, Eriksson CJ. The role of social isolation in the effects of alcohol on corticosterone and testosterone levels of alcohol-preferring and non-preferring rats. Alcohol Alcohol. 2006; 41:33-38. [PubMed: 16216823]

Armeli S, Carney MA, Tennen H, Affleck G, O’Neil TP. Stress and alcohol use: a daily process examination of the stressor-vulnerability model. J Pers Soc Psychol. 2000; 78:979-994. [PubMed: 10821203]

Becker HC, Lopez MF, Doremus-Fitzwater TL. Effects of stress on alcohol drinking: a review of animal studies. Psychopharmacology. 2011; 218:131-156. [PubMed: 21850445] 
Besheer J, Faccidomo S, Grondin JJ, Hodge CW. Effects of mGlu1-receptor blockade on ethanol selfadministration in inbred alcohol-preferring rats. Alcohol. 2008; 42:13-20. [PubMed: 18164577]

Besheer J, Faccidomo S, Grondin JJ, Hodge CW. Regulation of motivation to self-administer ethanol by mGluR5 in alcohol-preferring (P) rats. Alcohol Clin Exp Res. 2008; 32:209-221. [PubMed: 18162077]

Besheer J, Fisher KR, Grondin JJ, Cannady R, Hodge CW. The effects of repeated corticosterone exposure on the interoceptive effects of alcohol in rats. Psychopharmacology. 2012; 220:809-822. [PubMed: 22016195]

Besheer J, Grondin JJ, Cannady R, Sharko AC, Faccidomo S, Hodge CW. Metabotropic glutamate receptor 5 activity in the nucleus accumbens is required for the maintenance of ethanol selfadministration in a rat genetic model of high alcohol intake. Biol Psychiatry. 2010; 67:812-822. [PubMed: 19897175]

Campioni MR, Xu M, McGehee DS. Stress-induced changes in nucleus accumbens glutamate synaptic plasticity. J Neurophysiol. 2009; 101:3192-3198. [PubMed: 19357347]

Cannady R, Fisher KR, Durant B, Besheer J, Hodge CW. Enhanced AMPA receptor activity increases operant alcohol self-administration and cue-induced reinstatement. Addiction biology. 2012

Carney MA, Armeli S, Tennen H, Affleck G, O’Neil TP. Positive and negative daily events, perceived stress, and alcohol use: a diary study. J Consult Clin Psychol. 2000; 68:788-798. [PubMed: 11068965]

Chester JA, de Paula Barrenha G, DeMaria A, Finegan A. Different effects of stress on alcohol drinking behaviour in male and female mice selectively bred for high alcohol preference. Alcohol Alcohol. 2006; 41:44-53. [PubMed: 16299106]

Covault J, Tennen H, Armeli S, Conner TS, Herman AI, Cillessen AH, Kranzler HR. Interactive effects of the serotonin transporter 5-HTTLPR polymorphism and stressful life events on college student drinking and drug use. Biological Psychiatry. 2007; 61:609-616. [PubMed: 16920076]

Dawson DA, Grant BF, Ruan WJ. The association between stress and drinking: modifying effects of gender and vulnerability. Alcohol and alcoholism. 2005; 40:453-460. [PubMed: 15972275]

Dayas CV, Martin-Fardon R, Thorsell A, Weiss F. Chronic footshock, but not a physiological stressor, suppresses the alcohol deprivation effect in dependent rats. Alcohol Alcohol. 2004; 39:190-196. [PubMed: 15082455]

Fahlke C, Engel JA, Eriksson CJ, Hard E, Soderpalm B. Involvement of corticosterone in the modulation of ethanol consumption in the rat. Alcohol. 1994; 11:195-202. [PubMed: 8060519]

Fahlke C, Eriksson CJ. Effect of adrenalectomy and exposure to corticosterone on alcohol intake in alcohol-preferring and alcohol-avoiding rat lines. Alcohol Alcohol. 2000; 35:139-144. [PubMed: 10787388]

Fidler TL, LoLordo VM. Failure to find postshock increases in ethanol preference. Alcohol Clin Exp Res. 1996; 20:110-121. [PubMed: 8651440]

Funk D, Vohra S, Le AD. Influence of stressors on the rewarding effects of alcohol in Wistar rats: studies with alcohol deprivation and place conditioning. Psychopharmacology. 2004; 176:82-87. [PubMed: 15064919]

Gorin-Meyer RE, Wiren KM, Tanchuck MA, Long SL, Yoneyama N, Finn DA. Sex differences in the effect of finasteride on acute ethanol withdrawal severity in C57BL/6J and DBA/2J mice. Neuroscience. 2007; 146:1302-1315. [PubMed: 17428611]

Gourley SL, Taylor JR. Recapitulation and reversal of a persistent depression-like syndrome in rodents. Chapter 9, Unit 9 32. Curr Protoc Neurosci. 2009

Gourley SL, Wu FJ, Kiraly DD, Ploski JE, Kedves AT, Duman RS, Taylor JR. Regionally specific regulation of ERK MAP kinase in a model of antidepressant-sensitive chronic depression. Biol Psychiatry. 2008; 63:353-359. [PubMed: 17889834]

Grzywacz JG, Almeida DM. Stress and Binge Drinking: A Daily Process Examination of Stressor Pile-up and Socioeconomic Status in Affect Regulation. Int J Stress Manag. 2008; 15:364-380. [PubMed: 19578556]

Henniger MS, Spanagel R, Wigger A, Landgraf R, Holter SM. Alcohol self-administration in two rat lines selectively bred for extremes in anxiety-related behavior. Neuropsychopharmacology. 2002; 26:729-736. [PubMed: 12007743] 
Heyser CJ, Roberts AJ, Schulteis G, Koob GF. Central administration of an opiate antagonist decreases oral ethanol self-administration in rats. Alcohol Clin Exp Res. 1999; 23:1468-1476. [PubMed: 10512312]

Heyser CJ, Schulteis G, Koob GF. Increased ethanol self-administration after a period of imposed ethanol deprivation in rats trained in a limited access paradigm. Alcohol Clin Exp Res. 1997; 21:784-791. [PubMed: 9267526]

Hill MN, Hellemans KG, Verma P, Gorzalka BB, Weinberg J. Neurobiology of chronic mild stress: Parallels to major depression. Neuroscience and biobehavioral reviews. 2012; 36:2085-2117. [PubMed: 22776763]

Hodge CW, Samson HH, Tolliver GA, Haraguchi M. Effects of intraaccumbens injections of dopamine agonists and antagonists on sucrose and sucrose-ethanol reinforced responding. Pharmacol Biochem Behav. 1994; 48:141-150. [PubMed: 7913224]

Huang Z, Zhong XM, Li ZY, Feng CR, Pan AJ, Mao QQ. Curcumin reverses corticosterone-induced depressive-like behavior and decrease in brain BDNF levels in rats. Neuroscience letters. 2011; 493:145-148. [PubMed: 21334417]

Hyytia P, Kiianmaa K. Suppression of ethanol responding by centrally administered CTOP and naltrindole in AA and Wistar rats. Alcohol Clin Exp Res. 2001; 25:25-33. [PubMed: 11198711]

Johnson V, Pandina RJ. A longitudinal examination of the relationships among stress, coping strategies, and problems associated with alcohol use. Alcohol Clin Exp Res. 1993; 17:696-702. [PubMed: 8333603]

Jose BS, van Oers HA, van de Mheen HD, Garretsen HF, Mackenbach JP. Stressors and alcohol consumption. Alcohol Alcohol. 2000; 35:307-312. [PubMed: 10869253]

June HL, Torres L, Cason CR, Hwang BH, Braun MR, Murphy JM. The novel benzodiazepine inverse agonist RO19-4603 antagonizes ethanol motivated behaviors: neuropharmacological studies. Brain research. 1998; 784:256-275. [PubMed: 9518641]

Karatsoreos IN, Bhagat SM, Bowles NP, Weil ZM, Pfaff DW, McEwen BS. Endocrine and Physiological Changes in Response to Chronic Corticosterone: A Potential Model of the Metabolic Syndrome in Mouse. Endocrinology. 2010; 151:2117-2127. [PubMed: 20211972]

Knapp DJ, Overstreet DH, Huang M, Wills TA, Whitman BA, Angel RA, Sinnett SE, Breese GR. Effects of a stressor and corticotrophin releasing factor on ethanol deprivation-induced ethanol intake and anxiety-like behavior in alcohol-preferring P rats. Psychopharmacology. 2011; 218:179-189. [PubMed: 21643675]

Kranzler HR, Scott D, Tennen H, Feinn R, Williams C, Armeli S, Taylor RE, Briggs-Gowan MJ, Covault J. The 5-HTTLPR polymorphism moderates the effect of stressful life events on drinking behavior in college students of African descent. American journal of medical genetics. Part B, Neuropsychiatric genetics : the official publication of the International Society of Psychiatric Genetics. 2012; 159B:484-490.

Leitch MM, Ingram CD, Young AH, McQuade R, Gartside SE. Flattening the corticosterone rhythm attenuates 5-HT1A autoreceptor function in the rat: relevance for depression. Neuropsychopharmacology. 2003; 28:119-125. [PubMed: 12496947]

Lemos JC, Wanat MJ, Smith JS, Reyes BA, Hollon NG, Van Bockstaele EJ, Chavkin C, Phillips PE. Severe stress switches CRF action in the nucleus accumbens from appetitive to aversive. Nature. 2012; 490:402-406. [PubMed: 22992525]

Lloyd DA, Turner RJ. Cumulative lifetime adversities and alcohol dependence in adolescence and young adulthood. Drug and alcohol dependence. 2008; 93:217-226. [PubMed: 17980975]

Logrip ML, Zorrilla EP. Stress history increases alcohol intake in relapse: relation to phosphodiesterase 10A. Addiction biology. 2012; 17:920-933. [PubMed: 22741603]

Lopez MF, Doremus-Fitzwater TL, Becker HC. Chronic social isolation and chronic variable stress during early development induce later elevated ethanol intake in adult C57BL/6J mice. Alcohol. 2011; 45:355-364. [PubMed: 20880662]

Lowery EG, Spanos M, Navarro M, Lyons AM, Hodge CW, Thiele TE. CRF-1 antagonist and CRF-2 agonist decrease binge-like ethanol drinking in C57BL/6 $\mathrm{J}$ mice independent of the HPA axis. Neuropsychopharmacology. 2010; 35:1241-1252. [PubMed: 20130533] 
Lowery EG, Sparrow AM, Breese GR, Knapp DJ, Thiele TE. The CRF-1 receptor antagonist, CP-154,526, attenuates stress-induced increases in ethanol consumption by BALB/cJ mice. Alcohol Clin Exp Res. 2008; 32:240-248. [PubMed: 18162074]

Lynch WJ, Kushner MG, Rawleigh JM, Fiszdon J, Carroll ME. The effects of restraint stress on voluntary ethanol consumption in rats. Exp Clin Psychopharmacol. 1999; 7:318-323. [PubMed: 10609966]

Malinen H, Hyytia P. Ethanol self-administration is regulated by CB1 receptors in the nucleus accumbens and ventral tegmental area in alcohol-preferring AA rats. Alcohol Clin Exp Res. 2008; 32:1976-1983. [PubMed: 18782338]

McKinzie DL, Nowak KL, Yorger L, McBride WJ, Murphy JM, Lumeng L, Li TK. The alcohol deprivation effect in the alcohol-preferring $\mathrm{P}$ rat under free-drinking and operant access conditions. Alcohol Clin Exp Res. 1998; 22:1170-1176. [PubMed: 9726292]

Mizoguchi K, Shoji H, Ikeda R, Tanaka Y, Tabira T. Persistent depressive state after chronic stress in rats is accompanied by HPA axis dysregulation and reduced prefrontal dopaminergic neurotransmission. Pharmacol Biochem Behav. 2008; 91:170-175. [PubMed: 18675292]

Mizoguchi K, Yuzurihara M, Ishige A, Sasaki H, Chui DH, Tabira T. Chronic stress differentially regulates glucocorticoid negative feedback response in rats. Psychoneuroendocrinology. 2001; 26:443-459. [PubMed: 11337130]

Moller C, Wiklund L, Thorsell A, Hyytia P, Heilig M. Decreased measures of experimental anxiety in rats bred for high alcohol preference. Alcohol Clin Exp Res. 1997; 21:656-660. [PubMed: 9194920]

Morales-Medina JC, Sanchez F, Flores G, Dumont Y, Quirion R. Morphological reorganization after repeated corticosterone administration in the hippocampus, nucleus accumbens and amygdala in the rat. J Chem Neuroanat. 2009; 38:266-72. [PubMed: 19505571]

Myers RD, Holman RB. Failure of stress of electric shock to increase ethanol intake in rats. Q J Stud Alcohol. 1967; 28:132-137. [PubMed: 6030082]

Nacher J, Gomez-Climent MA, McEwen B. Chronic non-invasive glucocorticoid administration decreases polysialylated neural cell adhesion molecule expression in the adult rat dentate gyrus. Neuroscience letters. 2004; 370:40-44. [PubMed: 15489014]

Nash JF Jr. Maickel RP. Stress-induced consumption of ethanol by rats. Life Sci. 1985; 37:757-765. [PubMed: 4021738]

Nash JF Jr. Maickel RP. The role of the hypothalamic-pituitary-adrenocortical axis in post-stress induced ethanol consumption by rats. Prog Neuropsychopharmacol Biol Psychiatry. 1988; 12:653671. [PubMed: 2851859]

O'Callaghan MJ, Croft AP, Jacquot C, Little HJ. The hypothalamopituitary-adrenal axis and alcohol preference. Brain research bulletin. 2005; 68:171-178. [PubMed: 16325017]

O'Neill SE, Parra GR, Sher KJ. Clinical relevance of heavy drinking during the college years: crosssectional and prospective perspectives. Psychology of addictive behaviors : journal of the Society of Psychologists in Addictive Behaviors. 2001; 15:350-359. [PubMed: 11767268]

Olausson P, Kiraly DD, Gourley SL, Taylor JR. Persistent effects of prior chronic exposure to corticosterone on reward-related learning and motivation in rodents. Psychopharmacology. 2013; 225:569-77. [PubMed: 22983097]

Oster SM, Toalston JE, Kuc KA, Pommer TJ, Murphy JM, Lumeng L, Bell RL, McBride WJ, Rodd ZA. Effects of multiple alcohol deprivations on operant ethanol self-administration by highalcohol-drinking replicate rat lines. Alcohol. 2006; 38:155-164. [PubMed: 16905441]

Overstreet DH, Halikas JA, Seredenin SB, Kampov-Polevoy AB, Viglinskaya IV, Kashevskaya O, Badishtov BA, Knapp DJ, Mormede P, Kiianmaa K, Li TK, Rezvani AH. Behavioral similarities and differences among alcohol-preferring and -nonpreferring rats: confirmation by factor analysis and extension to additional groups. Alcohol Clin Exp Res. 1997; 21:840-848. [PubMed: 9267533]

Overstreet DH, Knapp DJ, Breese GR. Drug challenges reveal differences in mediation of stress facilitation of voluntary alcohol drinking and withdrawal-induced anxiety in alcohol-preferring $\mathrm{P}$ rats. Alcohol Clin Exp Res. 2007; 31:1473-1481. [PubMed: 17624999] 
Perrotti LI, Hadeishi Y, Ulery PG, Barrot M, Monteggia L, Duman RS, Nestler EJ. Induction of deltaFosB in reward-related brain structures after chronic stress. J Neurosci. 2004; 24:1059410602. [PubMed: 15564575]

Piazza PV, Le Moal M. The role of stress in drug self-administration. Trends Pharmacol Sci. 1998; 19:67-74. [PubMed: 9550944]

Piazza PV, Marinelli M, Rouge-Pont F, Deroche V, Maccari S, Simon H, Le Moal M. Stress, glucocorticoids, and mesencephalic dopaminergic neurons: a pathophysiological chain determining vulnerability to psychostimulant abuse. NIDA Res Monogr. 1996; 163:277-299. [PubMed: 8809864]

Raone A, Cassanelli A, Scheggi S, Rauggi R, Danielli B, De Montis MG. Hypothalamus-pituitaryadrenal modifications consequent to chronic stress exposure in an experimental model of depression in rats. Neuroscience. 2007; 146:1734-1742. [PubMed: 17481824]

Richardson HN, Lee SY, O'Dell LE, Koob GF, Rivier CL. Alcohol self-administration acutely stimulates the hypothalamic-pituitary-adrenal axis, but alcohol dependence leads to a dampened neuroendocrine state. Eur J Neurosci. 2008; 28:1641-1653. [PubMed: 18979677]

Rockman GE, Hall A, Hong J, Glavin GB. Unpredictable cold-immobilization stress effects on voluntary ethanol consumption in rats. Life Sci. 1987; 40:1245-1251. [PubMed: 3561150]

Rodd ZA, Bell RL, Kuc KA, Murphy JM, Lumeng L, Li TK, McBride WJ. Effects of repeated alcohol deprivations on operant ethanol self-administration by alcohol-preferring $(\mathrm{P})$ rats. Neuropsychopharmacology. 2003; 28:1614-1621. [PubMed: 12799615]

Saha TD, Chou SP, Grant BF. Toward an alcohol use disorder continuum using item response theory: results from the National Epidemiologic Survey on Alcohol and Related Conditions. Psychological medicine. 2006; 36:931-941. [PubMed: 16563205]

Schroeder JP, Overstreet DH, Hodge CW. The mGluR5 antagonist MPEP decreases operant ethanol self-administration during maintenance and after repeated alcohol deprivations in alcoholpreferring (P) rats. Psychopharmacology. 2005; 179:262-270. [PubMed: 15717208]

Shoji H, Mizoguchi K. Acute and repeated stress differentially regulates behavioral, endocrine, neural parameters relevant to emotional and stress response in young and aged rats. Behav Brain Res. 2010; 211:169-177. [PubMed: 20307586]

Sinclair JD, Senter RJ. Development of an alcohol-deprivation effect in rats. Quarterly journal of studies on alcohol. 1968; 29:863-867. [PubMed: 5705408]

Slopen N, Williams DR, Fitzmaurice GM, Gilman SE. Sex, stressful life events, and adult onset depression and alcohol dependence: are men and women equally vulnerable? Social science \& medicine. 2011; 73:615-622. [PubMed: 21782304]

Spanagel R, Montkowski A, Allingham K, Stohr T, Shoaib M, Holsboer F, Landgraf R. Anxiety: a potential predictor of vulnerability to the initiation of ethanol self-administration in rats. Psychopharmacology. 1995; 122:369-373. [PubMed: 8657835]

Spanagel R, Rosenwasser AM, Schumann G, Sarkar DK. Alcohol consumption and the body's biological clock. Alcohol Clin Exp Res. 2005; 29:1550-1557. [PubMed: 16156052]

Sparta DR, Ferraro FM 3rd, Fee JR, Knapp DJ, Breese GR, Thiele TE. The alcohol deprivation effect in C57BL/6J mice is observed using operant self-administration procedures and is modulated by CRF-1 receptor signaling. A Alcohol Clin Exp Res. 2009; 33:31-42.

Stewart RB, Gatto GJ, Lumeng L, Li TK, Murphy JM. Comparison of alcohol-preferring (P) and nonpreferring (NP) rats on tests of anxiety and for the anxiolytic effects of ethanol. Alcohol. 1993; 10:1-10. [PubMed: 8095393]

Stolerman I. Drugs of abuse: behavioural principles, methods and terms. Trends in Pharmacological Sciences. 1992; 13:170-176. [PubMed: 1604709]

Tidey JW, Miczek KA. Acquisition of cocaine self-administration after social stress: role of accumbens dopamine. Psychopharmacology. 1997; 130:203-212. [PubMed: 9151353]

van Erp AM, Miczek KA. Persistent suppression of ethanol self-administration by brief social stress in rats and increased startle response as index of withdrawal. Physiol Behav. 2001; 73:301-311. [PubMed: 11438355] 
Vendruscolo LF, Barbier E, Schlosburg JE, Misra KK, Whitfield TW Jr. Logrip ML, Rivier C, Repunte-Canonigo V, Zorrilla EP, Sanna PP, Heilig M, Koob GF. Corticosteroid-dependent plasticity mediates compulsive alcohol drinking in rats. J Neuroscience. 2012; 32:7563-7571.

Vengeliene V, Siegmund S, Singer MV, Sinclair JD, Li TK, Spanagel R. A comparative study on alcohol-preferring rat lines: effects of deprivation and stress phases on voluntary alcohol intake. Alcohol Clin Exp Res. 2003; 27:1048-1054. [PubMed: 12878910]

Volpicelli JR, Ulm RR, Hopson N. The bidirectional effects of shock on alcohol preference in rats. Alcohol Clin Exp Res. 1990; 14:913-916. [PubMed: 2088129]

Welte JW, Mirand AL. Drinking, problem drinking and life stressors in the elderly general population. Journal of studies on alcohol. 1995; 56:67-73. [PubMed: 7752635]

Willner P. Chronic mild stress (CMS) revisited: consistency and behavioural-neurobiological concordance in the effects of CMS. Neuropsychobiology. 2005; 52:90-110. [PubMed: 16037678]

Wise RA, Wang B, You ZB. Cocaine serves as a peripheral interoceptive conditioned stimulus for central glutamate and dopamine release. PLoS One. 2008; 3:e2846. [PubMed: 18682722] 


\section{Highlights}

Increase in alcohol self-administration after corticosterone in the drinking water.

Sucrose self-administration and motor activity not affected by corticosterone history.

Alcohol self-administration functionally dissociated from corticosterone levels.

Results suggest neuroadaptations modulate increased alcohol self-administration. 



Figure 1.

Transient increase in alcohol self-administration following corticosterone exposure $(7 \mathrm{~d}$ in drinking water). a) Total responses on the alcohol-reinforced lever were significantly increased on the first session following corticosterone exposure (CORT; $300 \mu \mathrm{g} / \mathrm{ml} ; 7 \mathrm{~d}$; $\mathrm{n}=10)$ relative to Water controls $(\mathrm{n}=10)$ and relative to the baseline $(\mathrm{B})$. Self-administration returned to levels similar to the Water group on the following sessions. b) On the first session following CORT exposure, cumulative alcohol lever responses in the CORT group were increased throughout the self-administration session, resulting in increased alcohol intake (inset). c) Plasma CORT levels after the first self-administration session following Water/CORT exposure were significantly decreased in the CORT group relative to the 
Water group and as compared to baseline confirming efficacy of the CORT exposure protocol. *signifies significant difference from Water group $(\mathrm{p}<0.05)$. + signifies significant difference from baseline. Values on graphs represent mean \pm s.e.m. 

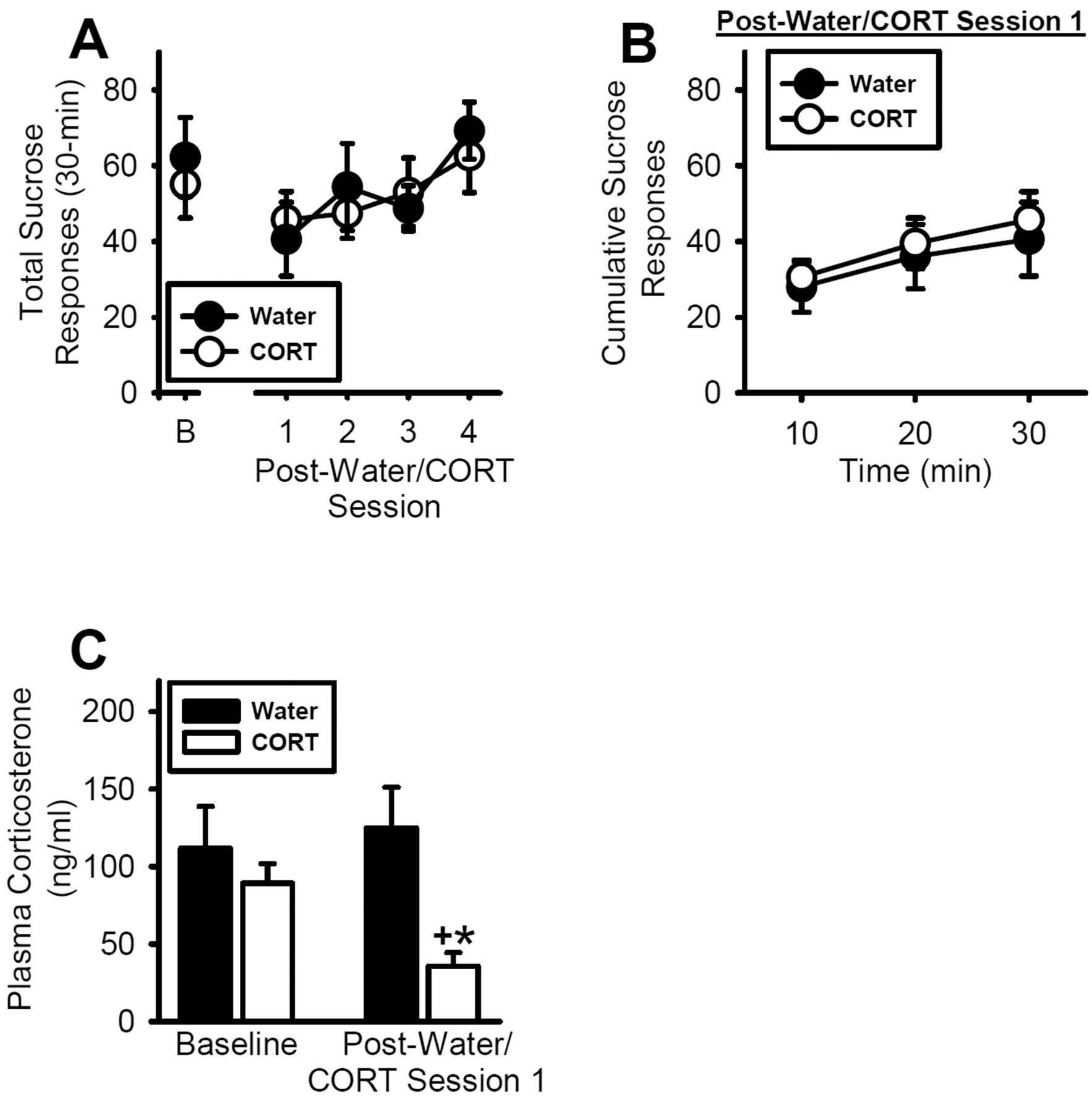

Figure 2.

Corticosterone exposure ( $7 \mathrm{~d}$ ) does not alter sucrose self-administration. a) Total responses on the sucrose-reinforced lever were not altered following corticosterone exposure (CORT; $300 \mu \mathrm{g} / \mathrm{ml} ; 7 \mathrm{~d} ; \mathrm{n}=12$ ) relative to Water exposure. b) Cumulative sucrose lever responses on the first session following Water/CORT exposure did not differ between the groups throughout the self-administration session. c) Plasma CORT levels after the first selfadministration session following Water/CORT exposure were significantly decreased in the CORT group relative to the Water group and as compared to baseline confirming efficacy of the CORT exposure protocol. *signifies significant difference from Water group $(\mathrm{p}<0.05)$. + signifies significant difference from baseline. Values on graphs represent mean \pm s.e.m. 


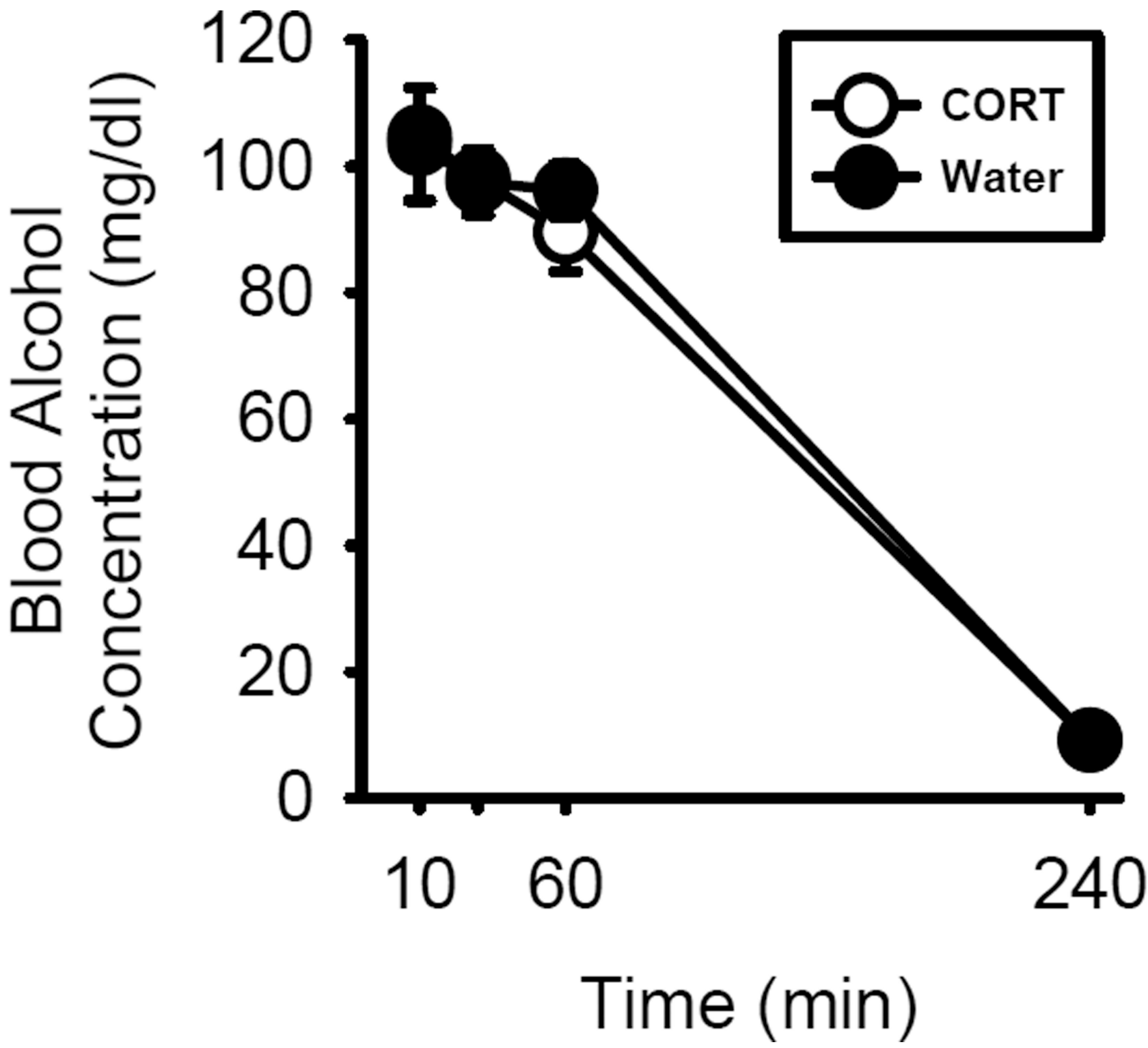

Figure 3.

Blood alcohol concentration is not altered by CORT exposure (7 d). Blood alcohol concentration following $1 \mathrm{~g} / \mathrm{kg}$ (IG) is not altered following the end of CORT exposure in rats with a history of alcohol self-administration $(\mathrm{n}=8 / \mathrm{grp})$. Values on graphs represent mean \pm s.e.m. 

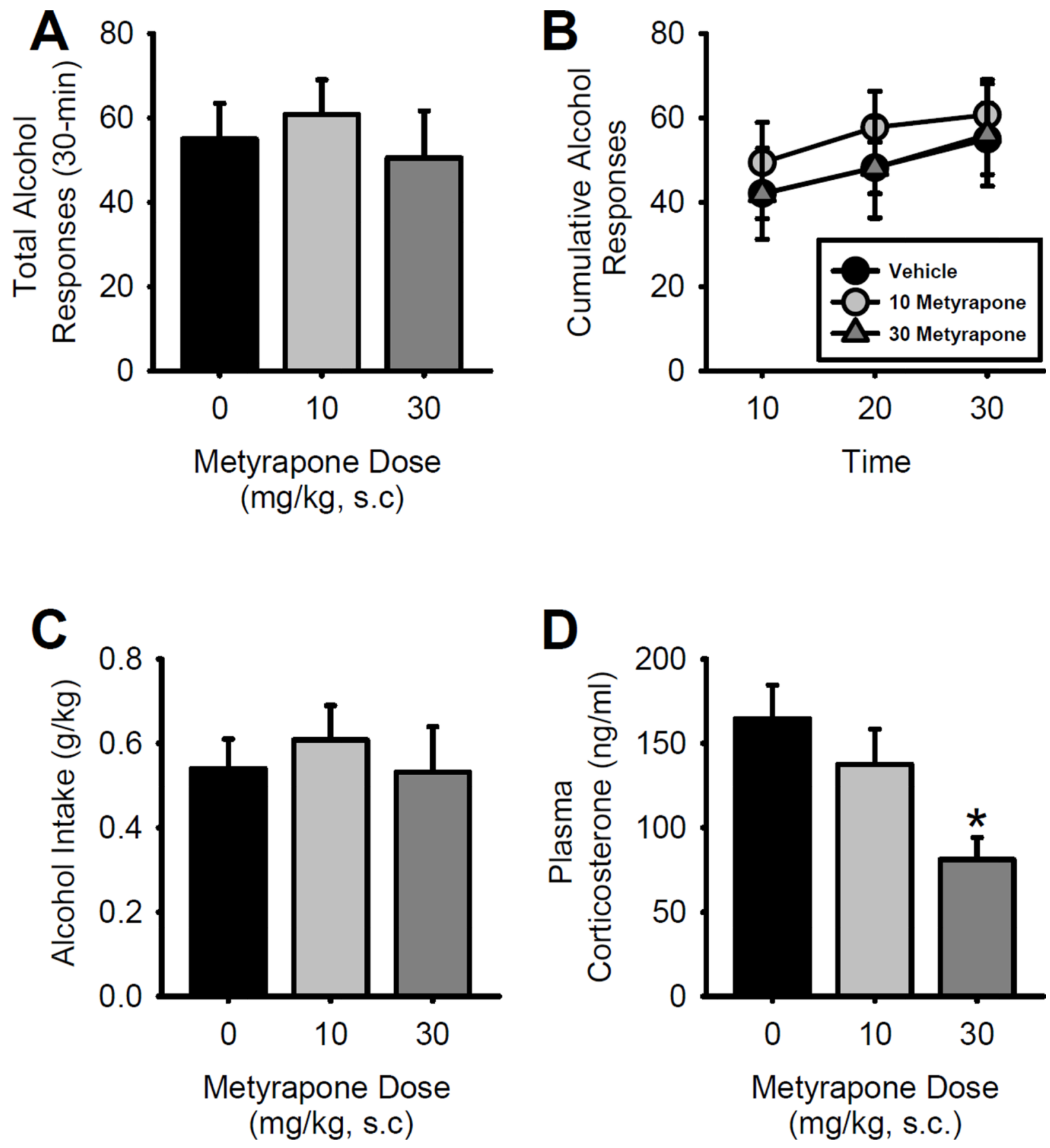

Figure 4.

Inhibition of CORT synthesis by metyrapone does not alter alcohol self-administration. a) Metyrapone pretreatment ( 10 or $30 \mathrm{mg} / \mathrm{kg}, \mathrm{SC} ; \mathrm{n}=9$ ) did not alter total alcohol-paired lever responses, b) cumulative responses or c) alcohol intake relative to vehicle (0). d) Plasma CORT levels were significantly reduced by $30 \mathrm{mg} / \mathrm{kg}$ metyrapone consistent with the compound's mechanism of action. *signifies significant difference from vehicle group $(\mathrm{p}<0.05)$. Values on graphs represent mean \pm s.e.m. 


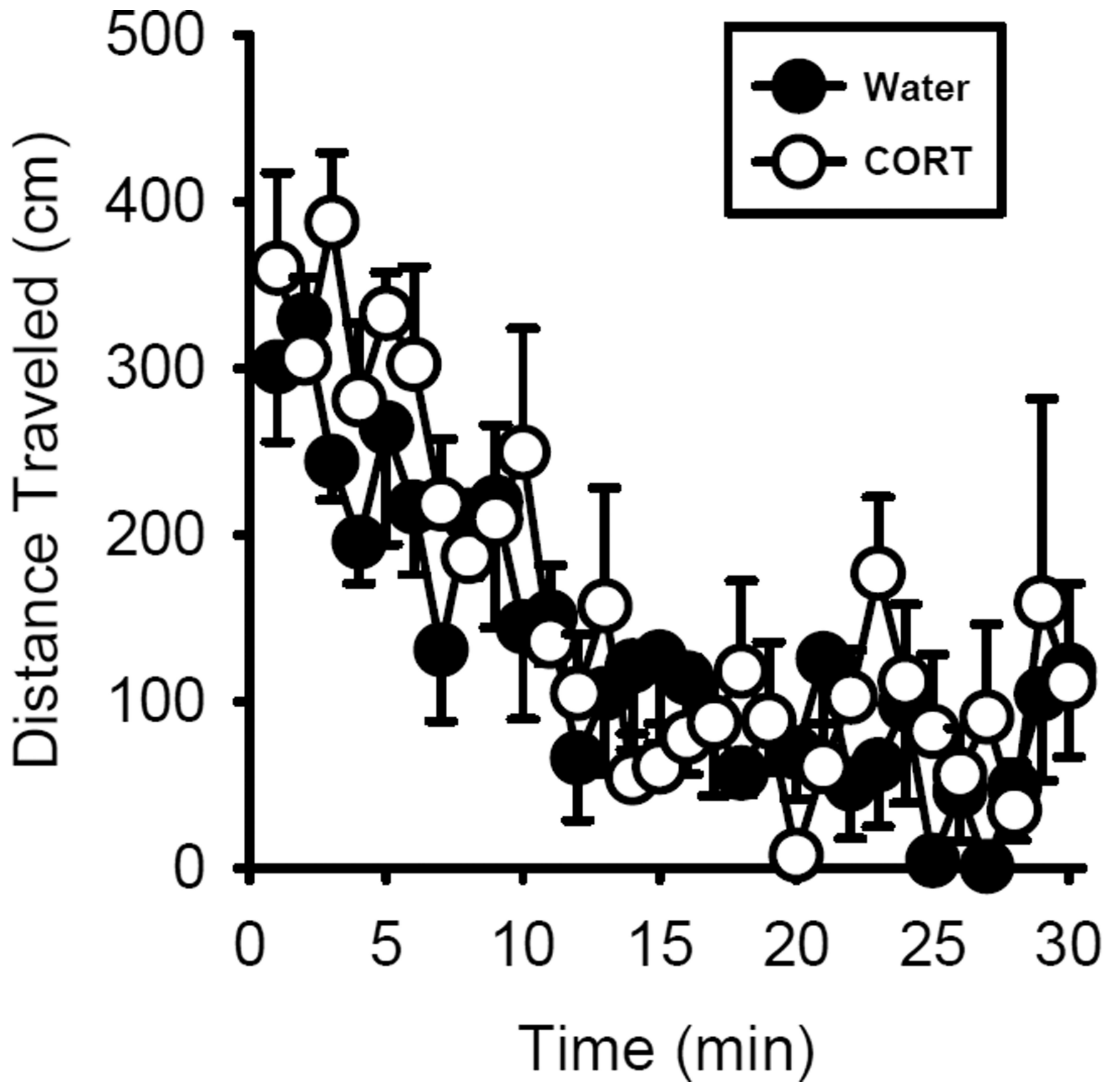

Figure 5.

Corticosterone exposure (7 d) does not alter locomotor activity in an open field. Distance traveled over time in the open field at the end of CORT exposure did not differ between the CORT group and the Water control group ( $\mathrm{n}=6$ /group) in rats with a history of alcohol selfadministration. Values on graphs represent mean \pm s.e.m. 


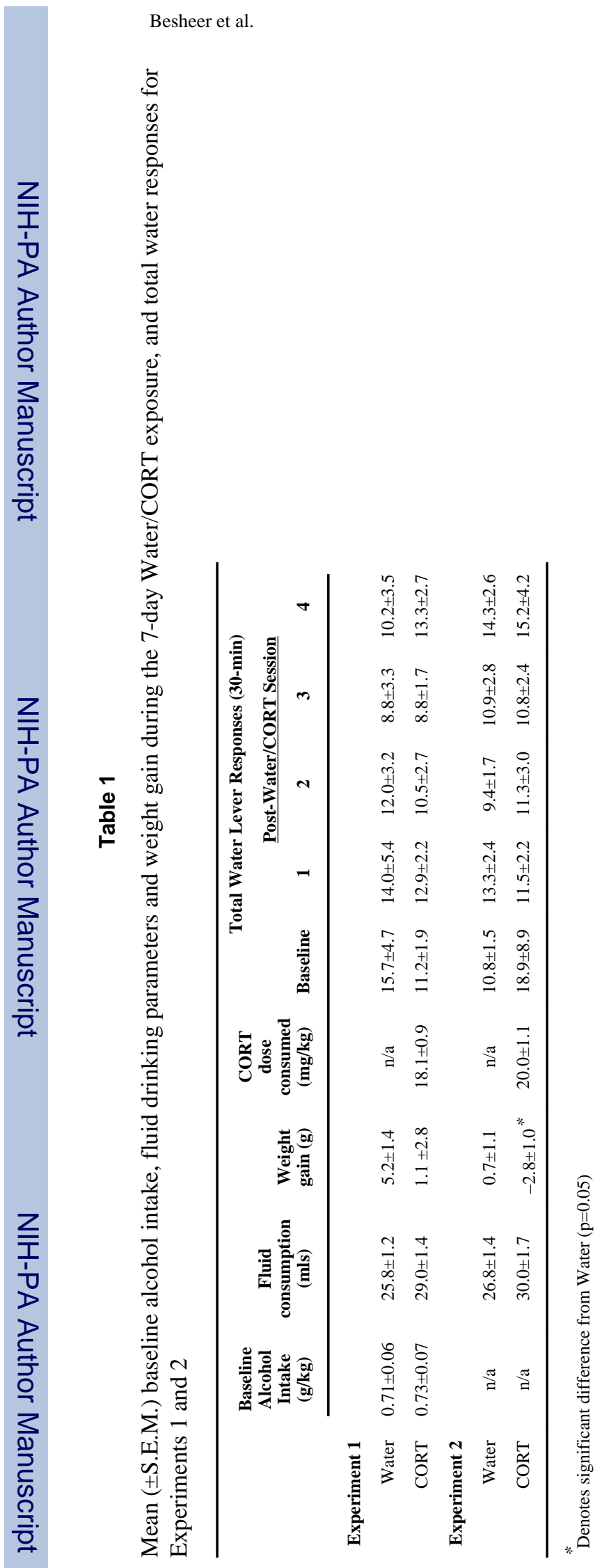

Neuropharmacology. Author manuscript; available in PMC 2014 September 01. 


\section{Table 3}

Experiment 3: Mean ( \pm S.E.M.) alcohol clearance measures after 1 g/kg (IG)

\begin{tabular}{lcc}
\hline Clearance Parameters & Water & CORT \\
\hline BAC at $0 \mathrm{~min}(\mathrm{mg} / \mathrm{dl})$ & $112.57 \pm 6.62$ & $98.46 \pm 13.05$ \\
Clearance Rate $(\mathrm{mg} / \mathrm{ml} / \mathrm{min})$ & $0.42 \pm 0.03$ & $0.42 \pm 0.01$ \\
Clearance Time (min) & $267.61 \pm 4.35$ & $263.24 \pm 3.88$ \\
Area Under Curve (AUC) & $14396.38 \pm 621.71$ & $13725.75 \pm 820.53$ \\
\hline
\end{tabular}

